\title{
Amplitude sensitive modulation-thermography the new way of moisture measurement in building materials
}

\author{
by K. A. Büscher ${ }^{1}$, H. Wiggenhauser ${ }^{2}$, W. Wild ${ }^{1}$ \\ 1 Universität Rostock, Institute for Measuring and Control Techniques, D-18057 Rostock, Germany \\ ${ }^{2}$ Federal Institute for Materials Research and Testing (BAM), D-12205 Berlin, Germany
}

\begin{abstract}
Most damages in buildings, particularly in old buildings, are a direct or indirect consequence of moisture. The causes can be leakages in compartments of the building, perigee or that areas of facades are exposed to driving rain. In addition the building structures contain salts in most cases which become mobile in moist materials and cause again indirect damages. Even after having taken measures of dewatering these damages can be still effective.

For a diagnosis of a moisture damage including the determination of its cause and the damage rate, it is necessary to measure the moisture in those building compartments. Effective measures of reconstruction make sense only after a through analysis of the damage. An analysis technique is demanded for detecting damages which is non-destructive, remote sensing and highly selective with respect to moisture and which should be able to locate large areas with excessive moisture. Unfortunately, for practical applications such a device for detecting moisture, fulfilling all the conditions mentioned above, is still not available on the market.
\end{abstract}

\section{Introduction}

Most damages in buildings, particularly in old buildings, are a direct or indirect consequence of moisture. The causes can be leakages in compartments of the building, moisture capillary suction from foundations or from areas exposed to driving rain. As a consequence, the salts contained in the building materials becomes mobile and causes further indirect damage. With cristallisation, the salt volume increases and causes destruction in near surface areas. Even after having taken measures of dewatering, these damages can still be progressing ${ }^{1}$.

For a diagnosis of a moisture damage including the determination of its cause and the damage rate, it is necessary to measure the moisture in those building compartments. Effective measures of reconstruction make sense only after a through analysis of the damage. An analysis technique is demanded for detecting damages which is nondestructive, remote sensing and highly selective with respect to moisture and which should be able to locate large areas with excessive moisture. Unfortunately, for practical applications such a device for detecting moisture, fulfilling all the conditions mentioned above, is still not available on the market ${ }^{2}$.

\section{Motivation}

In the eighties the first IR-reflectographic investigations were reported. Passive thermography does not provide highly contrasting results of moisture in brickwork ${ }^{3}$. The reflectographic method utilizes the absorption behaviour of water absorbed in building materials. The infrared absorption maxima of water can be found at the wavelengths 1,49 , $1,73,1,94$ and $2,97 \mu \mathrm{m}$. So these absorption bands are used for detecting moisture in building materials.

In measurements, moisture has been detected in brickwork with an illumination at wavelengths between 2 and $4 \mu \mathrm{m}$, by using an infrared system sensitive in the same working wavelength band. In figure 1.1 a thermogram is shown for a thoroughly wetted building brickwork without infrared radiation. Having an additional projection of infrared radiation, the contrast between wet and dry areas is much clearer in the reflectogram as can be seen in 
figure $1.2^{4}$. The thermogram shows the conventional measurement taken at a temperature difference of $20 \mathrm{~K}$ between inside and outside what typically is needed to detect damaged zones. At the top of the specimen, the temperature is higher than at the bottom, which corresponds to the internal moisture distribution. The heat conductivity of water is fifty times higher than of brickwork, resulting in a better heat transport in moist areas. In fig. 1.2 it is shown, that by using additional illumination of infrared radiation in the wavelength range between 2 and $4 \mu \mathrm{m}$, the contrast between $\mathrm{dry}$ and wet areas is improved. The moist masonery in the reflectogram indicates lower "temperatures" due the absorption of the radiation in this wavelength. With the use of infrared radiation, dry areas of the brickwork show higher temperatures, because there is less absorption of the illumination.

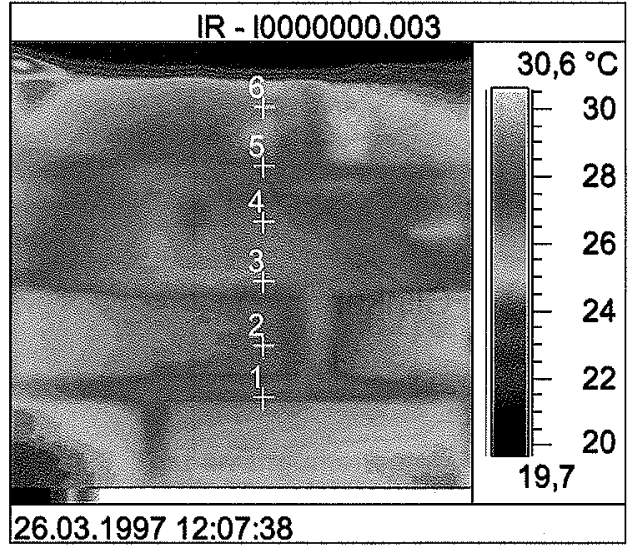

Fig. 1.1. Thermogram of moist masonery

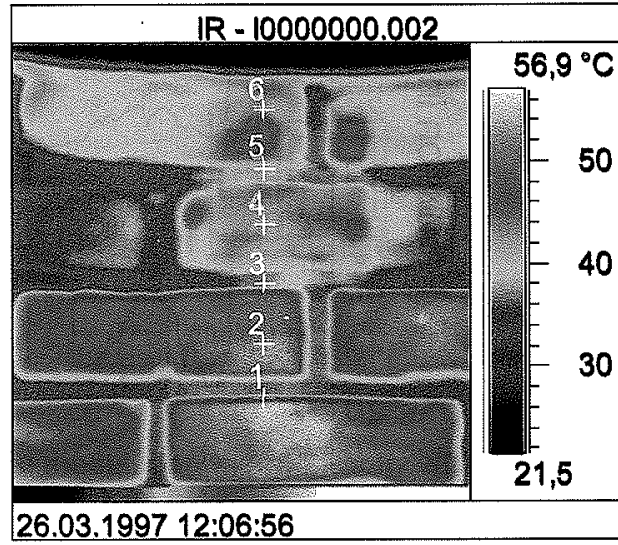

Fig. 1.2. Reflectogram of moist masonery

It is an advantage of IR-reflectrography to measure large areas with high contrast between wet and dry regions. However the quantitative determination of moisture in the brickwork can only be limited, because the results are strongly influenced by emission coefficient differences of the surface, by leaking radiation or by an inhomogeneous illumination due to the additional projection of radiation. Apart from this, the quantitative relation between remission intensity and moisture is uncertain. These disadvantages require a further analysis of the remission behaviour of building materials in the wavelength range between 1,3 and $3,1 \mu \mathrm{m}^{5}$.

\section{Preliminary Investigations}

It has been part of the preliminary investigations to analyse the relation between the remission from the building surface and its surface-moisture in detail. Also, the dynamic range of the reflexion-signals for all moisture levels is of great interest. The contributions resulting from spurious or leakage radiation are to be eliminated.

For this purpose in the past extensive remission tests with building materials have been carried out by BAM $^{6}$. Measurements of remission spectra of dry and wet building materials at wavelengths ranging from 0,3 to $13 \mu \mathrm{m}$ have clearly shown that in the infrared spectral range between 1 and $2 \mu \mathrm{m}$ the surface moisture can successfully be detected.

At the Rostock University, Department of Mechanical Engineering and Ship Technology, Institute of Measuring and Control Techniques, infrared spectra of deionized water, tap water and of a collection of building materials have been recorded. The results of these recordings have been compared to tests carried out at BAM. It is evident that there are well defined absorption bands of water absorbed in building materials which can be used for detecting the surface moisture. As given above the absorption maxima are at 1,49,1,73, 1,94 and 2,97 $\mu \mathrm{m}$. According to these results it is recommended to choose the detector in the near infrared 
range (Vidicon working range of wavelengths between 1,0 and $2,1 \mu \mathrm{m}$ ), hence the absorptions at $1,49,1,73,1,94$ and $2,97 \mu \mathrm{m}$ can be utilized for the detection, using interference filters with their maximum transmission at these wavelengths and with a bandwidth of $50 \mathrm{~nm}$.

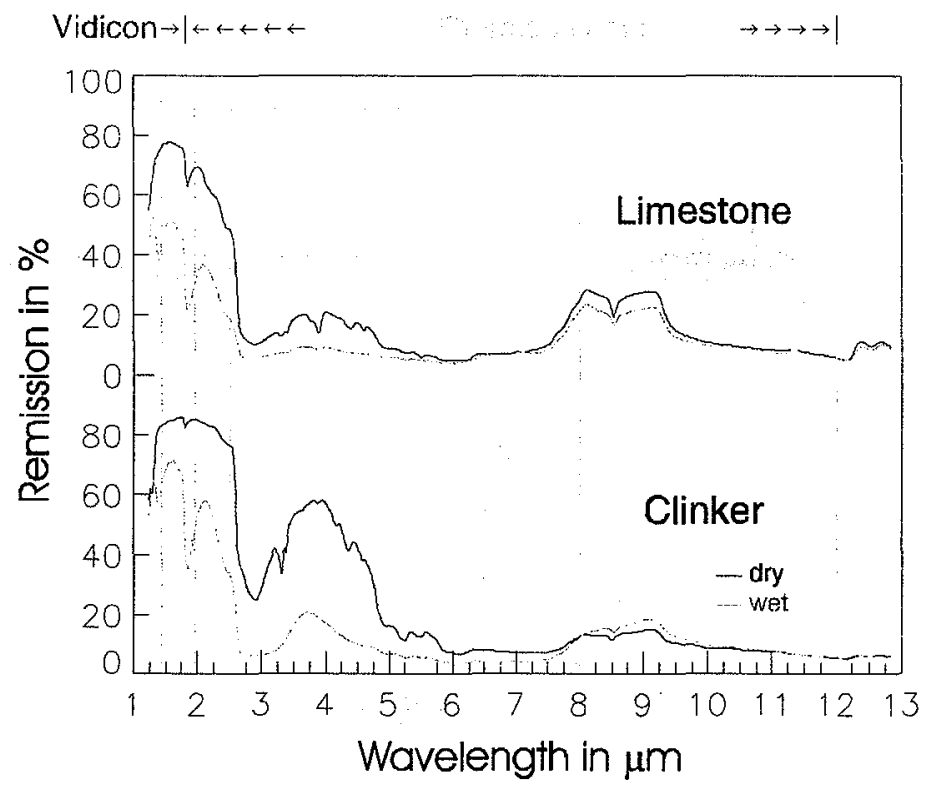

Fig. 2. Remission spectra of dry and wet building materials (from ref. 5)

\section{Amplitude sensitive modulation thermography with point recording}

For testing purposes the amplitude sensitive modulation thermography has been set up for point measurements. In reflectographic investigations, typically the building component under investigation is excited independently from the recording infrared camera. In the amplitude sensitive modulation experiment the signal from the detector is fed into the lock-in amplifier which receives its reference from the chopper in the beam of the additional illumination. This arrangement allows a selective measurement of the reflection originating from the modulated radiation. The use of these components ensures to record just the reflected radiation which is exclusively in the wavelength range of the interference filter.

One advantage of this method is that there is no influence of leakage radiation. The components used are essentially the same as those used in infrared thermography, but the selected image sector is a circular area with $2 \mathrm{~cm}$ diameter which is, after subsequent integration, given as a spot value.

The test arrangement is shown in figure 3. Through the use of the modulated illumination by light with the wavelengths of the water absorptions (using interference filters) it is possible to extract the specific reflection signal using a lock-in amplifier.

The arrangement described above has been used to test several building materials. It is of course desirable to have a high resolution in the range of low surface moisture which is hardly or not visible for the human eye. 


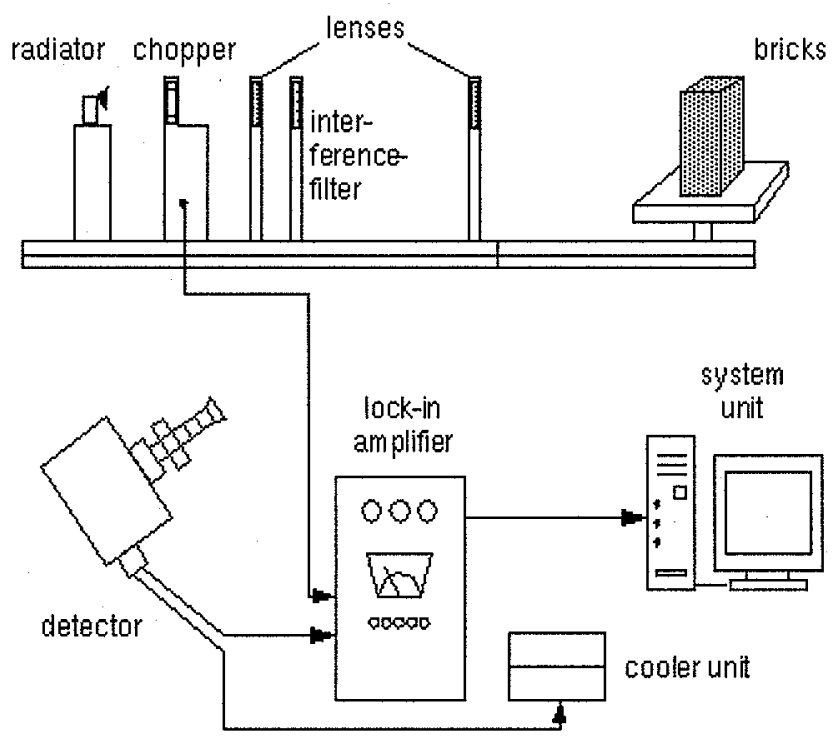

Fig. 3. Test arrangement amplitude sensitive modulation thermography with point recording

Figure 4 shows an example of the measurements of the relative remission from a brick illuminated at the wavelengths of $1,0,1,49,1,73,1,94$ and $2,97 \mu \mathrm{m}$. With the use of the illumination at $1,0 \mu \mathrm{m}$ the dynamic range is the lowest and it is possible to employ this wavelength as a reference. The other illumination wavelengths show a greater dynamic range. Applying the wavelength $1,94 \mu \mathrm{m}$ for additional radiation resulted in a significantly better resolution and a greater measuring dynamic in the range of lower surface moisture.

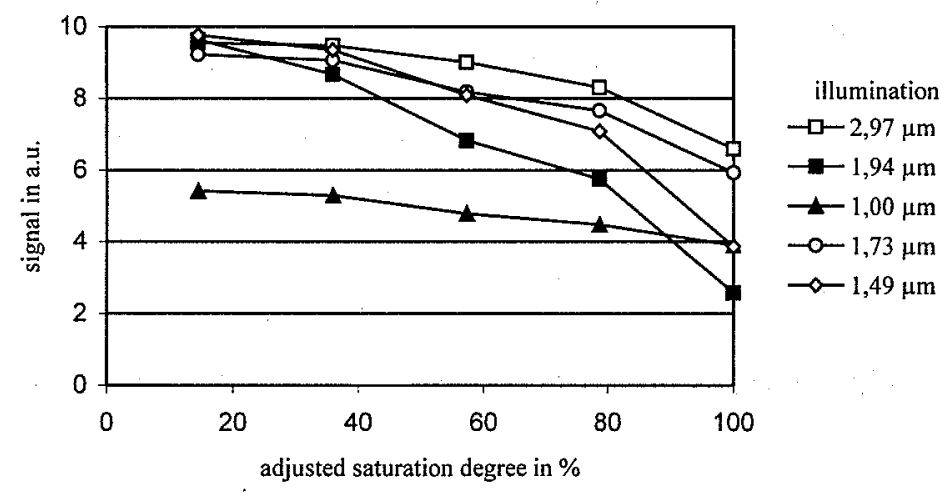

Fig. 4. Remission of clinker in the wavelengths of $1,0,1,49,1,73,1,94$ and $2,97 \mu \mathrm{m}$ 


\section{Amplitude sensitive modulation thermography with an imaging system}

In order to perform the amplitude sensitive modulation thermography with an imaging system the equipment has to be adapted.

For recording infrared images a Hamamatsu Vidicon camera is used having a wavelength range of $0,8-2 \mu \mathrm{m}$ and an image repetition rate of 25 images per second. Due to the recording characteristic of the imaging system the chopper applied before cannot be used for technical reasons. The chopper is replaced by a radiator which is modulated in the frequency range between 0,01 and $0,5 \mathrm{~Hz}$. Because in the imaging system all points of the infrared image are used for the detection, a lock-in amplifier would theoretically be required for each point of the image. A numerical data analysis is applied for this purpose. This is simplified by the sinoidal modulation of the intensity of the illumination ?

The modulated radiation is filtered using interference filters as described above, i.e. the object investigated is radiated only by those wavelengths, which utilize the absorption maxima of water bands.

Prior to the data analysis the infrared images recorded during the excitation still contain leakage radiation, reflected radiation and the self-radiation of the object. The subsequent data analysis completely eliminates those parts resulting from leakage radiation ${ }^{8}$. In figure 5 the test arrangement is presented for the amplitude sensitive modulation thermography with an imaging system.

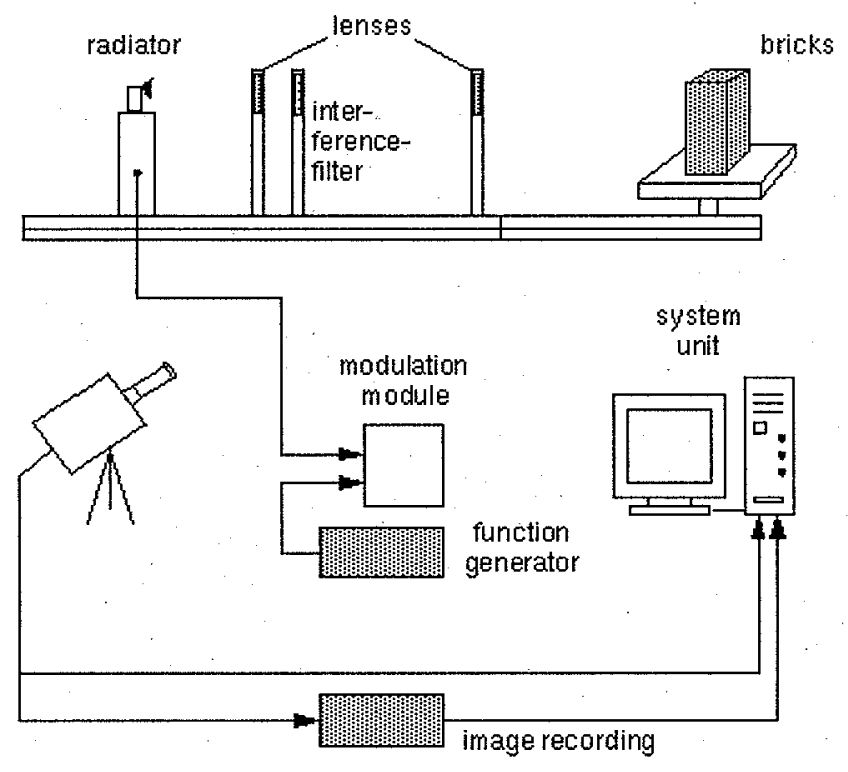

Fig. 5. Imaging amplitude sensitive modulation-thermography

\section{Results}

The method has been tested on a number of building materials under laboratory conditions. As a radiator a quartz lamp with $1000 \mathrm{~W}$ power was used.

The building materials have been prepared under well-defined conditions with several surface moisture levels in order to test the sensitivity of this method. The modulation frequencies are varied in the range between 0,01 and $0,3 \mathrm{~Hz}$ in order to characterise their influences significantly. 


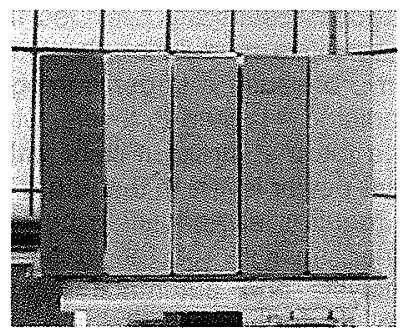

Fig. 6. Photograph of the specimens

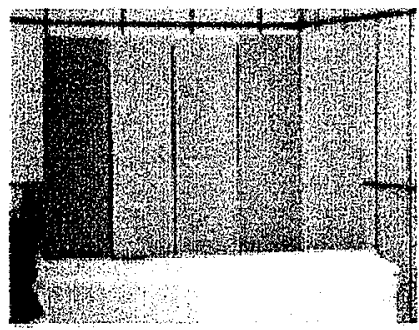

Fig. 7. Passive thermogram of the specimens

Bricks were the first objects under investigation. In fig. 6 there is a photograph of five clinkers with different surface moisture levels. In fig. 7 is a passive thermogram (without illumination) of the specimens. The different surface moisture of the specimens is not clearly visible in the thermogram. The thermogram is shown for comparison with the following results.

In the lock-in experiments a modulated illumination is used in the wavelength of $1,0 \mu \mathrm{m}$ at a frequency of $0,1 \mathrm{~Hz}$. From previous investigations it is known that illumination at $1,0 \mu \mathrm{m}$ is not advantageous for a high contrast between dry and wet bricks. In figure 8 the amplitude image is shown. It is evident that the surface moisture is not detectable. Through the lock-in data analysis the influence of leaking radiation is eliminated. For further investigations the amplitude image with the illumination wavelength at $1,0 \mu \mathrm{m}$ will be used as reference.

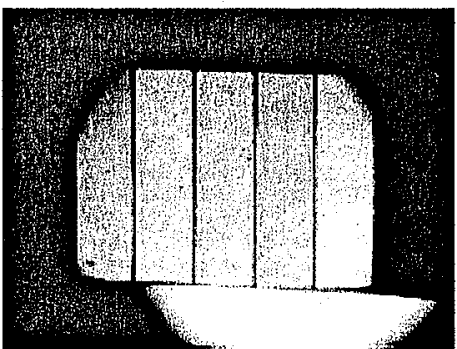

Fig. 8. Amplitude image of bricks with illumination with the wavelength of $1,0 \mu \mathrm{m}$

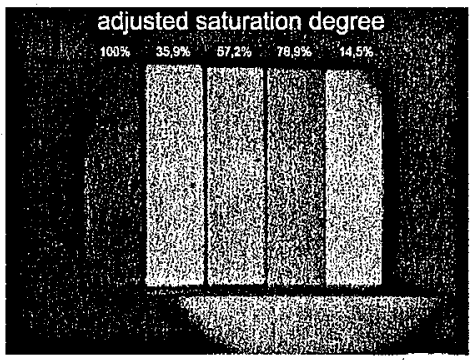

Fig. 9. Amplitude image of bricks with illumination with the wavelength of $1,94 \mu \mathrm{m}$

To amplify the effect an interference filter with a wavelength of $1,94 \mu \mathrm{m}$ for the illumination is used. The experimental conditions like the modulation frequency and the specimens have been unchanged. The resulting amplitude image is presented in figure 9 .

With the use of the distinct absorption band of water at 1,94 $\mu \mathrm{m}$ the best result are achieved, so that the differences in amplitudes between the wet and the dry brick is largest. The amplitude image is amplified with a factor of $Q=2,8$ to correct the wavelength dependent sensitivity of the detector ${ }^{10}$.

\section{Discussion}

The special utilization of water absorption bands has proven to be useful for the detection of surface moisture in building materials applying both conventional infrared systems of the wavelength of $2,97 \mu \mathrm{m}$ and near infrared of the wavelengths $1,49,1,73$ and $1,94 \mu \mathrm{m}$, if Vidicon systems are used. The disturbing influence of leaking radiation can be eliminated in the amplitude sensitive modulation thermography, because the signals coming from the modulated radiation can be extracted. 
The amplitude images recorded make evident that good results are provided from the surface moisture detection with the imaging amplitude sensitive modulation thermography. So far the area to be tested has been limited to $0,16 \mathrm{~m}^{2}$, because a larger homogeneous illumination cannot be provided yet. The power of the radiator is limited to levels, where the interference filters might be damaged due to the implied thermal stress. Filters with larger diameter, or other protective measures, may enable higher power levels in the future.

The amplitude sensitive modulation thermography requires a modulation between the radiator and the camera to allow a simplified Fourier analysis of the data. Further developments will include automatic on-line data analysis and automatic selection of modulation frequency and wavelength of illumination to further discriminate between moisture effects and other signal contributions.

\section{Acknowledgements}

The guidance and help of Dipl.-Ing. W. Hammer and Dipl.-Ing. B. Günther (BAM S.13) for the point measurements (section 4 ) is greatly appreciated. The valuable suggestions of Dr. F. Weise (BAM VII.31) made a fast progress in the work possible.

\section{REFERENCE}

[1] LESCHNIK (W.) - Welchen Beitrag kann die Feuchtemeßtechnik zur Qualitätssicherung bei der Bauwerkssanierung leisten? in: H. Wiggenhauser, H.S. Müller (eds), Proc. Feuchtetag 1995, Bundesanstalt für Materialforschung und -prüfung Berlin, Berlin, 1995, pp. 1-12.

[2] CAMMERER (F.) - Wärme- und Kälteschutz im Bauwesen und in der Industrie. SpringerVerlag, Tutzing, 1995, pp. 120-124.

[3] BÖTTCHER (B.), RICHTER (H.), - Verfahren zur Messung der Zusammensetzung und örtlichen Konzentrationen von Stoffen an Oberflächen. Offenlegungsschrift DE 3204146 A 1, Deutsches Patentamt, München, 1983.

[4] KROGMANN (D.) - Lokalisation von Feuchte in Baustoffen mit der Methode der Reflektografie. Diploma Universität Rostock Institute for Measuring and Control Techniques, unpuplished diploma, Rostock, 1997.

[5] ARNDT (D.), BORCHARDT (K.), CROY (P.), GEYER (E.), HENSCHEN (J.), MAIERHOFER (C.), NIEDACK-NAD (M.), RUDOLPH (M.), SCHAURICH (D.), WEISE (F.), WIGGENHAUSER (H.) - Anwendung und Kombination zerstörungsfreier Prüfverfahren zur Bestimmung der Mauenwerksfeuchte im Deutschen Dom. BAMForschungsbericht 200, Wirtschaftsverlag NW, Bremerhaven, 1994, pp. 36-50.

[6] GEYER (E.), ARNDT (D.), GÜNTHER (B.) - Bestimmung der Reflexion von trockenen und befeuchteten Baustoffen im Wellenlängenbereich 0,3 bis 2,5 $\mu \mathrm{m}$ für die IR-optische Bestimmung der Feuchte. in: H. Wiggenhauser, .S. Müller (eds), Proc. Feuchtetag 1995, Bundesanstalt für Materialforschung und -prüfung Berlin, Berlin, 1995, pp. 176-185.

[7] WU (D.) - Lock-In Thermographie für die zerstörungsfreie Werkstoffprüfung und Werkstoff-charakterisierung. Dissertation, Universität Stuttgart, Stuttgart, 1996.

[8] MANDELIS (A.) - Progress in Photothermal and Photoacoustic Science and Technology. Non-destructive Evaluation (NDE) Volume II, PTR Prentice Hall, Toronto, 1994.

[9] WILD (W.), BÜSCHER (K. A.), WIGGENHAUSER (H.) - Amplitude sensitive modulationthermography to measure moisture in building materials. SPIE Thermosense XX, Orlando 1998, Vol. 3361, pp. 156-162.

[10] RICHARDSON (A. J.), WIEGAND (C. L.) - Distinguishing vegetation from soil background information. Photogrammetric Engineering and Remote Sensing 43, Weslaco 1977. 